\title{
JTF Web-Enabled Faculty and Student Tools for More Effective Teaching and Learning Through Two-Way, Frequent Formative Feedback
}

\section{Prof. Stephen J Krause, Arizona State University}

Stephen J. Krause is professor in the Materials Program in the Fulton School of Engineering at Arizona State University. He teaches in the areas of bridging engineering and education, capstone design, and introductory materials science and engineering. His research interests include strategies for web-based teaching and learning, misconceptions and their repair, and role of formative feedback on conceptual change. He has co-developed a Materials Concept Inventory for assessing conceptual knowledge of students in introductory materials engineering classes. He is currently conducting research on web-based tools for teaching and learning, misconceptions and strategies and tools to promote conceptual change in materials courses.

\section{Dr. Dale R Baker, Arizona State University}

Dale Baker is the 2013 awardee of the National Association for Research in ScienceTeaching Distinguished Contributions to Science Education Through Research Award for her work on equity. She is also a fellow of the American Association for the Advancement of Science and the American Educational Research Association. In additon to equity issues in science, her research has focused on engineering education and teacher professional development.

\section{Dr. Adam R Carberry, Arizona State University}

Adam R. Carberry, Ph.D., is an Assistant Professor at Arizona State University in the Fulton Schools of Engineering. He earned a B.S. in Materials Science Engineering from Alfred University, and received his M.S. and Ph.D., both from Tufts University, in Chemistry and Engineering Education respectively. Dr. Carberry was previously an employee of the Tufts' Center for Engineering Education \& Outreach.

\section{Dr. Terry L. Alford, Arizona State University \\ Casey Jane Ankeny PhD, Arizona State University}

Casey Ankeny is a lecturer in the School of Biological and Health Systems Engineering at Arizona State University. Her research focuses on the evaluation of student-centered strategies with respect to achievement, attitude, and persistence.

\section{Dr. Milo Koretsky, Oregon State University}

Milo Koretsky is a Professor of Chemical Engineering at Oregon State University. He received his B.S. and M.S. degrees from UC San Diego and his Ph.D. from UC Berkeley, all in Chemical Engineering. He currently has research activity in areas related engineering education and is interested in integrating technology into effective educational practices and in promoting the use of higher-level cognitive skills in engineering problem solving. His research interests particularly focus on what prevents students from being able to integrate and extend the knowledge developed in specific courses in the core curriculum to the more complex, authentic problems and projects they face as professionals. Dr. Koretsky is one of the founding members of the Center for Lifelong STEM Education Research at OSU.

\section{Dr. Bill Jay Brooks, Oregon State University}

Bill Brooks is a postdoctoral scholar in the School of Chemical, Biological, and Environmental Engineering at Oregon State University. His Ph.D used written explanations to concept questions to investigate technology mediated active learning in the undergraduate chemical engineering classroom. He current interests involve using technology to enhance educational practices in promoting conceptual understanding. $\mathrm{He}$ is the primary programmer of the AIChE Concept Warehouse and his current focus is on its continued development, specifically creating and integrating Interactive Virtual Labs.

Dr. Debra M. Gilbuena, Oregon State University 
Debra Gilbuena is a postdoctoral scholar in the School of Chemical, Biological, and Environmental Engineering at Oregon State University. Debra has an M.BA, an M.S, and four years of industrial experience including a position in sensor development. Sensor development is also an area in which she holds a patent. She currently has research focused on student learning in virtual laboratories and the diffusion of educational interventions and practices.

\section{Dr. Cindy Waters, North Carolina A\&T State University}

Cindy K. Waters is an Assistant Professor in the Mechanical Engineering at NCA\&T State University. She received her B.S. and M.S from Virginia Tech in Materials Science and Engineering Department and a $2004 \mathrm{PhD}$ in Mechanical Engineering, from NCA\&T. Her research is in the development and characterization of novel syntactic foams and various porous metals via powder metallurgy and foam casting. She is also significantly involved in engineering education research in the areas of assessment studies of classroom material science pedagogical implementations; case studies in various engineering disciplines and; engineering faculty barriers to adopt evidence-based (or nontraditional) teaching methods . She serves as the College of Engineering liaison to ASEE and advises the Society of Women Engineers student chapter and leads the students in developing and implementing yearly outreach events for the K-8 female community. She is author of many peer-reviewed conference proceeding for the ASEE Annual Meetings and the FIE meetings.

\section{Prof. Brady J. Gibbons, Oregon State University}

Dr. Brady Gibbons is an Associate Professor of Materials Science in the School of Mechanical, Industrial, \& Manufacturing Engineering at Oregon State University. His research specializes in structure-processproperty relationships in multifunctional thin film materials. His group focuses on processing, novel instrumentation development, and integration science; new dielectric, superconducting, semiconducting, and pyroelectric materials for energy conversion and energy storage; ferroelectric and piezoelectric thin films for microelectromechanical systems; scanning probe and x-ray diffraction characterization methods; and spectroscopic ellipsometry. Specifically he is interested in developing novel integration science strategies to combine material functionalities that result in significantly enhanced, or even new, properties. Prior to arriving at OSU he spent eight years at Los Alamos National Laboratory (LANL) as a postdoctoral researcher and member of the technical staff. There, his research on 2nd generation superconducting wire led to an R\&D 100 Award in 2004. He received his Ph. D. in Materials from the Pennsylvania State University in 1998. Dr. Gibbons is a 2012 NSF CAREER awardee, as well. That program is designed to develop new environmentally benign piezoelectric materials, which can be used for a variety of sensing and actuation applications including sonar, ultrasound, energy harvesting, and microelectromechanical systems.

\section{Prof. William Joseph Stuart P.E., Oregon Institute of Technology}

\section{BIOGRAPHICAL SKETCH}

Professor Joe Stuart

\section{PROFESSIONAL PREPARATION}

B.Sc., Metallurgical/Mechanical Engineering, University of Nevada at Reno (1969) M.Sc., Physical Science, University of Southampton, UK (1972)

\section{APPOINTMENTS}

2006 to Present Program Director Manufacturing Engineering Technology, OIT 2011 to Present Associate Professor, MMET Department, Oregon Institute of Technology 2004 to 2011 Assistant Professor, Oregon Institute of Technology, Klamath Falls 2002 to 2004 National Accounts Manager, Wagner Electronics 1998 to 2002 President/Owner, Best Tech USA 1985 to 1998 VP and General Manager, Alumaweld Boats Inc \& Rogue Trailers Inc. 1984 to 1985 Manufacturing Rep MDA Associates 1981 to 1984 Quality Engineer, International Memories Inc. 1980 to 1981 Design Engineer Balteau Standard 1977 to 1980 Field Engineer, Wisar Construction 1975 to 1977 General Manager Milthorn Toleman Ltd., UK 1974 to 
1975 Chief Scientist, Puerto Rico Nuclear Center 1972 to 1974 Engineering Consultant, EPA 1969 to 1970 Metallurgical Engineer, Republic Steel Inc.

Professional Societies:

American Society of Engineering Education, Life time member Society of Manufacturing Engineering, American Society of Mechanical Engineers

\section{PUBLICATIONS}

(i)Most Closely Related [1] W.J. Stuart 'Problem Based Case Learning - Composite Materials Course Development - Examples and classroom reflections' NEW Conference, Oct 2011 [2] W.J. Stuart and Bedard R. (EPRI) 'Ocean Renewable Energy Course Evolution and Status' presented at Energy Ocean Pacific \& Oregon Wave Energy Trust Conference, Sept. 2010. [3] W.J. Stuart, Wave energy 101, presented at Oregon Wave Energy Symposium, Newport, OR, Sept. 2009. [4] W.J. Stuart, Corrosion considerations when designing with exotic metals and advanced composites, presented at Corrosion Conference of Exotic Metals, Park City, UT, 2009. [5] W.J. Stuart, Ruth Loring, Ed Webster, Frank Cox, Composite materials course development using problem based case learning techniques, National Educators Workshop, Greensboro, NC, 2009. [6] W.J. Stuart, Three pronged approach to sustainability at OIT, presented to faculty and staff at OIT 2008 Fall Convocation, 2008. [7] W.J. Stuart, Sustainability workshop, presented to faculty and staff at OIT 2006 Fall Convocation, 2006. (ii) Other [1] W.J. Stuart, Successful programs that have been enriched by industry and engineering education connections, Proceedings of ASEE Conference, Chicago, IL, 2006.

\section{SYNERGISTIC ACTIVITIES}

- Course development for Ocean Renewable Energy for Manufacturing Engineering Technology and Renewable Energy Engineering students: developed and taught a new undergraduate dual listed course, Ocean Renewable Energy, in spring 2010. This course has now also been developed and is offered (and has been taught) as a 'Distance Education' course. • Course and lab development for Advanced Composites for Manufacturing Engineering Technology and Mechanical Engineering Technology students: developed and taught a new undergraduate dual listed course, Advanced Composites, in spring 2009 and winter 2010. - Student advising and course integration in sustainable concepts and life cycle analysis and material selection considerations. - Innovations in teaching: used innovative teaching methods to enhance the learning experience through introducing problem based case learning techniques in classes and course structure; presentation of paper in National Educators Workshop.

\section{COLLABORATORS AND OTHER AFFILIATIONS}

(i) Collaborators and Co-Editors Frank Cox, Edmonds Community College; Ruth M. Loring, Nashville State Community College; Wangping Sun, Oregon Institute of Technology; Ed Webster, Institute for Professional Training and Education; John Anderson, Oregon Institute of Technology

(ii) Special Material Expert Curriculum development for National Resource Center-CAM composite materials course for National Resource Center at Edmonds Community College.

\section{Mr. Sean Maass}

Currently pursuing a Masters Degree in Materials Science and Engineering. Passionate about enhancing Engineering Education across the globe as well as continuing to learn more about Materials, Design, Manufacturing, Data Mining and Analysis, and Statistics.

\section{Prof. Candace K Chan, Arizona State University}

Candace K. Chan is an assistant professor in Materials Science and Engineering in the School for Engineering of Matter, Transport and Energy at Arizona State University. She teaches introductory materials science to undergraduate engineering majors and is exploring the role of frequent, formative feedback and web-based teaching and learning on student engagement and understanding of materials concepts. Dr. Chan also teaches an advanced course on electrochemical energy conversion and storage and leads a group of undergraduate, graduate, and postdoctoral researchers focused on the design and characterization of novel materials for batteries and photoelectrochemical applications. 


\title{
JTF Web-Enabled Faculty and Student Tools for More Effective Teaching and Learning through Two-Way, Frequent Formative Feedback
}

\begin{abstract}
JTF (Just-in-Time-Teaching with Interactive Frequent Formative Feedback) is an NSF TUES Type 2 project with an overall goal of implementing web-enabled tools and resources that facilitate the strategies, practices, and assessments that use two-way frequent formative feedback to improve student attitude, learning, and achievement. The project is a collaboration of faculty at four institutions of higher education. In this paper we are reporting progress toward achieving the following goals of the project: 1) to develop engagement, feedback, and assessment resources for web-based suites of instructor Just-in-Time-Teaching tools and student Just-inTime-Learning resources for interactive instruction that supports and facilitates web and classroom engagement pedagogy for more effective teaching and learning; 2) to build a community of practice that supports implementation of JTF pedagogy; 3) to investigate how instructors use JTF feedback and assessment to identify and diagnose student learning issues and the teaching strategies used to address them; 4) to assess the effect of the JTF pedagogy on student attitude, learning, and persistence, as well as effectiveness in resolving student learning issues; 5) to assess the potential for broader adaptation of JTF pedagogy in other engineering domains; and 6) to broadly disseminate and diffuse JTF strategies and resources to a wide audience to facilitate greater adaptation of JTF pedagogy.
\end{abstract}

Some important highlights of progress over the past year in include the following. An important instructor resource for automated Muddiest Point data collection was activated in June 2013 and brought online as part of the Concept Warehouse (CW), cw.edudiv.org, web site that also has real-time feedback for over 1600 Conceptest questions. The real-time Muddiest Point student feedback capability includes PDF output with a word cloud and tabulated end-of-class Muddiest Point student responses. An important and popular student learning resource has been Muddiest Point YouTube materials science videos at www.youtube.com/user/MaterialsConcepts. By early 2014 the 18-month old site had acquired over 1,200 subscribers and had over 140,000 hits with more than 600,000 minutes of viewing. A survey of collaborating faculty showed almost all agreed or strongly agreed that being involved in JTF has: 1) had made them more reflective teachers; 2) had motivated them to change their classroom practice; 3) had made their students more engaged as a result of the changes they were implementing in my classroom teaching practice; and 4) helped them better understand their students' learning. The impact of JTF teaching strategies on student attitude at four diverse institutions found from a Student Value Survey on usefulness of Muddiest Points to learning found, that there was a positive average of 64\% for Interest / Attainment Value, 85\% average of Utility Value, and 84\% agreement that the personal cost of effort was low. During 5 classes in Fall 2013 term, student persistence from the class second week to the final exam was 204 out of 211 or $97 \%$. In working to impact other disciplines with JTF, a 2013 ASEE workshop had 28 participants who unanimously agreed they envisioned incorporating at least one of the web-based teaching and learning strategies from the workshop into their course(s). A final highlight regarding dissemination is that Wiley Publishing is using four types of JTF student learning resources in their Wiley Plus e-Learning web platform in the next edition of two materials textbooks. They include: 35 Muddiest Point Tutorial and Example Problem videos; a Muddiest Point data collection tool; a visual glossary vocabulary building web flash card resource; and a vocabulary definition-term, multiple-choice set of quick questions. The body of the paper will discuss the results of the JTF project in more detail. 


\section{Introduction}

JTF (Just-in-Time-Teaching with Interactive Frequent Formative Feedback) is an NSF TUES Type 2 project with an overall goal of implementing web-enabled tools and resources that facilitate the strategies, practices, and assessments that use two-way frequent formative feedback to improve student attitude, learning, and achievement. Well-designed frequent formative feedback has potential to enhance both instructor teaching and student learning and can be referred to as "two-way" feedback." ${ }^{1}$ For the JTF project, the process enables more effective instruction with instructor Just-in-Time-Teaching tools and for student Just-in-Time-Learning resources, as catalyzed by faculty-student interactions through two-way frequent formative feedback mechanisms. It helps students monitor their construction of knowledge and contributes to the self-regulation that leads to deeper conceptual learning and the achievement of their learning goals ${ }^{2}$. The ease-of-implementation, impact, and effectiveness of the JTF pedagogy are being tested in collaboration with faculty in diverse settings at four institutions of higher education. The project is targeting the six major goals described below and this paper will describe and discuss the goal-associated objectives, activities, accomplishments to this time.

The first goal was to web-enable successful previous project (CCLI 1) engagement, feedback, and assessment resources by expanding resources into web-based suites of instructor Just-inTime-Teaching tools and student Just-in-Time-Learning resources for interactive instruction that supports and facilitates use of JTF pedagogy for more effective teaching and learning. The second goal was to build a community of practice that supports implementation of JTF pedagogy through instructor discussions, web meetings, and workshops to understand JTF barriers and benefits and the change in teaching beliefs and classroom practice that occurs over time. The third goal was to investigate how instructors use JTF feedback and assessment to identify and diagnose student learning issues and the teaching strategies used to address them. The fourth goal was to assess the effect of the JTF pedagogy on student attitude, learning, and persistence, as well as effectiveness in resolving student learning issues. The fifth goal was to assess the potential for broader adaptation of JTF pedagogy in other engineering domains. The sixth goal was to broadly disseminate and diffuse JTF strategies and resources to a wide audience to facilitate greater adaptation of JTF pedagogy.

\section{JTF Project Results and Discussion}

\section{Goal One of Developing Web-Enabled Instructor and Student Resources}

For the first goal of developing the instructor Just-in-Time-Teaching tools and student Just-inTime-Learning resources, the working objective was to develop and characterize the extent of implementation and use of web-enabled instructor Just-in-Time-Teaching tools on the Concept Warehouse site and student Just-in-Time-Learning resources on open web sites such as YouTube, Quizlet and SlideShare. The activities, results, and outcomes are described below.

New and improved teaching and learning tools were implemented into a web environment. In particular, two instructor Just-in-Time-Teaching tools were web-enabled on the Concept Warehouse (CW) web site at http://jimi.cbee.oregonstate.edu/concept_warehouse/ ${ }^{3}$. One was the end-of-class, Muddiest Point Student Reflection which was web-enabled for easy, automated data collection and reporting ${ }^{4}$. It also included a new built-in Word Cloud feature for a quick analysis of the most significant Muddiest Points for a given class. Automating Muddy Point data collection and analysis has encouraged greater faculty participation for diagnosing student 
learning issues and adjusting instruction to address them. A second tool that was a web-enabled collection of 114 Conceptest question sets used for classroom clicker questions or pre-post topic concept quizzes, both of which are now easier to use via the web, which can increase usage.

For students, three complementary Just-in-Time-Learning web resources were developed and implemented. Today, research-informed conceptualization of learning views it as a process by which students actively construct their own knowledge ${ }^{5}$. In this model, students interact with topical content in different settings, including social engagement with other students, and connect with prior knowledge to build a conceptual framework of retrievable knowledge and understanding of the new content ${ }^{6}$. The student resources available in the project will promote lifelong learning skills. One popular resource was the set of 12 Muddiest Point YouTube tutorial screencasts at www.youtube.com/user/MaterialsConcepts. During the 18 months of development and use the site has received over 140,000 views and acquired over 1,200 subscribers. These videos provide fast feedback and self-tutoring to help students address their own learning issues. Their effectiveness is due, in part, to the fact that their content focuses on a given topic's Muddiest Point responses generated by students themselves. A second complementary resource is the Materials Vocabulary Building Resource site at http://Quizlet.com/MatSciasu. The site contains over 500 materials science terms and has capabilities to present a given term/definition/image in the form of visual vocabulary e-flash cards or e-vocabulary games. A third complementary resource that was created contains slide sets for each one of the Muddiest Point YouTube tutorial videos at http://www.slideshare.net/mseasuslides/presentations. Students viewed these YouTube slide sets over 5000 times and can download them so they can take notes while watching Muddiest Point YouTube videos. Instructors at collaborating institutions may be interested in creating some of their own resources, as described later in the report.

Overall, the project developed and implemented a suite of two types of instructor Just-in-TimeTeaching tools implemented on Concept Warehouse for automated data collection and assessment. Additionally, a suite of popular student Just-in-Time-Learning resources have been implemented on open web sites such as YouTube Muddiest Point videos, Quizlet vocabulary tool, and SlideShare for YouTube video slide sets. Further development of JTF web-enabled resources include the following:

1) New and expanded instructor Just-in-Time-Teaching tools will be developed on Concept Warehouse including more ConcepTest question sets such as in the area of manufacturing and materials.

2) Development will begin in creation of an electronic self tutorial based on ConcepTest questions on the Concept Warehouse web site.

3) A third tool that will potentially be developed is an "App" for collecting Muddiest Point data. This would have the potential to greatly broaden and streamline usage of Muddy Point student feedback and instructor teaching adjustment.

4) Collaborating faculty will be encouraged to align Muddiest Point YouTube videos to appropriate classes that have similar content and learning outcomes. There is an element of the "flipped-class" pedagogy with this approach, but there is greater instructor feedback, guidance and facilitation of conceptual learning with the JTF pedagogy. 


\section{Goal Two of Building a Community of Practice}

For the second goal the working objective was, to build a community of practice and characterize it by documenting dialogue and outcomes of instructors' meetings, discussions and understandings of JTF barriers and benefits, and instructor change that occurs as a result of implementing JTF pedagogy. As such, a JTF community of practice is being developed through monthly web meetings, workshops, and web communication. Initial discussions of barriers and benefits in implementing JTF pedagogy show good progress. This is demonstrated by a survey of collaborating faculty which showed that almost all agreed or strongly agreed that being involved in JTF has: 1) had made them more reflective teachers; 2) had motivated them to change their classroom practice; 3 ) had made their students more engaged as a result of the changes they were implementing in their classroom teaching practice; and 4) helped them better understand their students' learning. However, perceptions of barriers and benefits that arose from implementing JTF pedagogy were also documented through discussions at monthly meetings. A summary of the discussions by collaborating faculty was that common barriers to implementing JTF pedagogy included: 1) the length of class time, 2) the time to analyze and devise a response, 3 ) the difficulty in establishing a routine and 4) low level of student participation. These issues are being ameliorated since the automated Concept Warehouse data collection web site came online. Future actions for the JTF community of practice to continue to be developed through monthly web meetings, a workshop, and web communication.

\section{Goal Three of Showing Instructors Use JTF to Adjust Instruction for Students' Needs}

For the third goal of investigating instructor use of JTF for students' needs, the working objective was to document and characterize how instructors use JTF feedback and assessment information to adjust instruction to respond to students learning needs and issues. This area was studied and reported in an FIE conference publication which described three faculty experiences with JTF in terms of short vignettes ${ }^{4}$. These are presented below.

Specific feedback was collected for the FIE 2013 conference in the form of faculty vignettes about their experience using Muddiest Points in their own classrooms. Excerpts of these vignettes are presented here.

Vignette 1 - Full Professor: "Initially, when I started to use 'muddiest points', the goal was to elicit confusing concepts from students in order to respond to them; however, over six semesters, the 'muddiest point' strategy has evolved into much more than responding to student issues. It opened a channel of communication and mutual trust between the students and me, which turned an instructor's monologue into a student instructor dialogue. As such, the interaction enhanced the student learning experience as well as the teacher's instructional experience. Much more than 'muddiest points' are elicited from comments including alternate conceptions, vocabulary issues, rushed teaching, bad handwriting, questions of curiosity, and comments on related student experiences. Students can reflect on their learning over a class as well as discover the issues their fellow students are struggling with. With student 'muddiest point' input, improved teaching strategies can help diminish previously difficult conceptions. Overall, 'muddiest points' enhances both student and teacher metacognition about learning and instruction, respectively."

Vignette 2 - Assistant Professor: "My foray into using muddiest point reflections began when a colleague suggested the tool as a method to engage students. After two semesters of using muddiest point reflections, I've come to the realization that the tool provides mutual gains for both my students and me. Muddy points revealed in my first semester have led me to make 
changes not only during the current semester, but beyond to the following year. The knowledge gained from my students encouraged me to try new approaches including video tutorials, jigsaw activities, and in-class activities. As a professor, I like to believe that I can generally tell when something isn't clear. Muddiest points is the tool that helps confirm or deny my intuition"

Vignette 3 - Assistant Professor: "Working with a close colleague, I was encouraged to try addressing the current needs of students by using their own strengths and weaknesses. The 'muddiest points' technique is a form of Just-in-Time Teaching (JITT) that I find is much less intimidating than traditional JITT. The entire lecture is not modified to suit the previous students' comments but the students do feel they are a part of the process when their own words are used to clear up muddy points. Students are made a part of the learning team; they are the players and the faculty member is the coach unlike in a traditional classroom when the faculty is a performer on stage and the students are mere audience members.”

Comments from the vignettes show dramatic change in the ways in which instructors view their teaching, both in day-to-day teaching and how to adjust instruction for more effective learning in future semesters. Instructor and students are part of a teaching and learning team that benefits both in their professional learning as well as with their personal satisfaction from the class.

\section{Goal Four of Assessing Impact of JTF Project on Students}

For the fourth goal of assessing impact on students, the working objective was to measure and assess the impact of JTF pedagogy on student attitude, learning, and persistence. To assess student attitude, a new Student Value survey was developed and administered to assess impact of the JTF project on students. Five classes at 4 institutions all had very positive results discussed here. For the five Fall 2013 term classes student persistence was also measured. It was found that, from the second week of a course to the final exam in that course, student persistence was 204 remained out of 211 that were present the second week or 97\% persistence. These results are in line with those of $95 \%$ for a single investigator using JTF pedagogy ${ }^{3}$. It should be commented that a significant majority of the students were taking an outside-of-major materials course that was required by their degree program. These are very interesting results that need both additional data as well as investigation into the underlying reasons for such outcomes.

Also, data in Table 1 on impact of JTF teaching strategies on student attitude, learning, and persistence showed positive results from collaborating institutions. Shown below are results and analysis of a Student Value survey regarding the usefulness of Muddiest Points in their learning.

1) Interest/Attainment Value: Interest or intrinsic value is an individual's anticipated enjoyment of engaging in a particular activity. Related to interest value is attainment value or an individual's perception of how the activity contributes to the conception of who he or she is fundamentally. Results suggested that the majority of students found muddiest point reflection to positively impact their experience in the class.

2) Utility Value: Utility value is an individual's perception of the advantages that result from engaging in the task for future goals or rewards. Results suggest that students overwhelming found the material learned in their course to be of value to them in their current and future endeavors as learners and professionals.

3) Cost: Cost represents an individual's perception of sacrifices required, including effort, time, and psychological impact, for successful impact of an activity. Results suggest that students did not find muddiest point reflections to be a frustrating activity that took too much time and effort. 
4) Appeal: The final two questions pertained to the students' desire to see muddiest point reflection used in other courses as well as whether they would recommend a course with this muddiest point reflections to a friend. The majority of students (77\%) agreed that they would like to see this tool used in their other courses, while overwhelmingly (93\%) recommending the course to a friend. This final result is likely impacted by more than just the muddiest point reflections including the course content and the instructors themselves.

It can be seen from the results above that the use of muddiest point reflections is a simple intervention that is capable of having major impact on the delivery of course content. The benefit to such two-way formative feedback is the associated gain for both instructors and students. The instructor vignettes frame the muddiest point reflections as a catalyst for change in pedagogical practice. The vignettes reported that the muddiest points provide a "channel of communication and mutual trust" between the students and the instructor. That channel provides a way for them to have a dialogue between one another, in turn restructures the role of the teacher as "performer" to teacher as "coach". This role shift allows students to voice their opinions as a means to impact course content delivery. Instructors can then use student input to "confirm or deny the intuition" of what they feel that might need to be changed to improve the class.

From a student perspective, the survey revealed overwhelmingly positive value toward the muddiest point reflections. Students saw this opportunity as a way to positively impact interest, attainment, and utility value without too much negatively associated cost. Such results suggest that students found muddiest point reflections improved the course in a way that made the course more enjoyable and valuable. This increase in value resulted in high appeal for the course by students and a likelihood of recommending the course to a friend. While this final result is likely impacted by the course content and the instructors themselves, the instructors can still appreciate that students view using such activities as a means to obtain positive student reviews.

Table 1. Student Value of Muddiest Point Reflections: Results $\mathrm{n}$ (instructors) $=4$ and $\mathrm{n}$ (students) $=140$

\begin{tabular}{|l|c|c|}
\hline INTEREST/ATTAINMENT VALUE & Agree & Disagree \\
\hline motivated me to do well in the course & $\mathbf{5 9 \%}$ & $\mathbf{4 1 \%}$ \\
\hline was an effective way to increase engagement & $\mathbf{7 9 \%}$ & $\mathbf{2 0 \%}$ \\
\hline helped me better understand my own learning & $\mathbf{6 9 \%}$ & $\mathbf{3 1 \%}$ \\
\hline increased my level of responsibility & $\mathbf{5 9 \%}$ & $\mathbf{4 1 \%}$ \\
\hline
\end{tabular}

\begin{tabular}{|c|c|c|}
\hline UTILITY VALUE & Agree & Disagree \\
\hline will be of value after graduation & $81 \%$ & $19 \%$ \\
\hline was useful in career and/or graduate school goals & $79 \%$ & $21 \%$ \\
\hline helped me see relevance of eng to the real word & $87 \%$ & $13 \%$ \\
\hline helped me learn importance of mat science to engineering & $93 \%$ & $7 \%$ \\
\hline helped me learn importance of manufacturing to engineering & $88 \%$ & $12 \%$ \\
\hline
\end{tabular}

\begin{tabular}{|l|c|c|}
\hline COST & Agree & Disagree \\
\hline required too much effort & $17 \%$ & $83 \%$ \\
\hline made me frustrated and anxious & $14 \%$ & $86 \%$ \\
\hline required too much time & $15 \%$ & $85 \%$ \\
\hline
\end{tabular}




\section{Goal Five to Assess Potential of Using JTF in Other Engineering Domains}

For the fifth goal of assessing potential of JTF in other engineering domains, the working objective was to characterize and assess the level of interest from other engineering domains for use of the types of strategies and resources available with JTF pedagogy. A workshop was organized for engineering instructors on JTF strategies and tools given at the ASEE 2013 conference. To assess the potential for broader adaptation of JTF pedagogy in other engineering domains, a survey about JTF pedagogy was developed by the JTF project evaluator and given to the 28 participants. Of the 19 respondents who filled out the post-workshop exit survey, 18 agreed or strongly agreed that, "I envision incorporating at least one of the strategies from the workshop into my course(s)." I person did not respond. This positive attitude of this response was further reinforced by the fact that 16 out of 19 respondents agreed or strongly agreed that , "The workshop has inspired me to continue to learn about student engagement strategies that I can use in my classroom." The workshop goals, results and outcomes are summarized below.

The overall goal of the workshop was to explore and discover cyber-enabled means of promoting and facilitating more effective ways to improve student attitude, learning, \& persistence with the following guided activities. These included:

1) Refresh principles of "How People Learn"

2) Show evidence-based research for engineering classes and how to use:

Frequent formative feedback

Classroom practice: shifting from traditional to engagement

Student engagement implementation \& assessment

3) Introduce cyber-learning resources and tools

4) Consider joining a community of practice

Each of the above subjects were addressed and then followed by an extension activity. Here we summarize the activity and the feedback:

Workshop Activity 1: Reflect on a specific change you have made in your instruction (e.g., active learning, concept inventory, online modules, web-based tool, or any other changes):

Many of the changes are student-focused including online videos addressing student misconceptions, group work with industrial connections, and frequent formative feedback. These are some feedback quotes.

"Add online video on specific topic. Common reoccurring mistakes/misconceptions. Had to learn video, take time to make, unsure about impact on students, said they were helpful”

"Change: took a dull lab activity in statistical data analysis and analyzed candy data in class and did data analysis in class in groups. Why the change? Student complaints and no one applying it in projects. Impact: More data analysis after the change than before in final projects”

"Video chunks: short instructional video, pose question/quiz at the end of the video, student attempt and next video gives solution; Improved project completion, grades, and retention”

Workshop Activity 2: Briefly look over the 5 ECLIPSE (a teaching self-assessment survey) categories and select one category per table to give your feedback for assessing implementation of student engagement teaching and learning in the engineering classroom. 
The participants gave feedback on a variety of aspects related to ECLIPSE, including implementation, relevance to ABET student outcomes a-k and "How People Learn", and wording. Feedback quotes are mixed and the survey need modification. These are some of them.

"Would make more sense if students and/or TAs scored? Score my own course and use it to build the class around these principles. Seems like it would be hard to have an observer get the full picture of the course. Bet this seems like a great tool if used a couple of times.”

"Is this for class period or for semester? Cannot do all of the content items in an individual class session. Student vs. teacher outcome? It should be about how were the students engaged with the content? Are you evaluating the instructor of student learning?”

"16: depends on course, more for ET than engineering, 17 ?, 18 appropriate for senior design more than earlier course, 19, 20- not applicable to every class to every class; doesn't really measure culture."

Workshop Activity 3: Reflect on one specific cyber-tool you would like to use in your classroom (e.g., Conceptests, Concept Warehouse, Quizlet, YouTube, SlideShare or any other tools):

The most popular cybertool was the muddiest point feedback feature on Concept Warehouse which was demonstrated in the workshop. We asked the participants about the muddiest point of the workshop. Other popular tools included Quizlet and the Muddiest Point YouTube Videos. We also received feedback about other cybertools in use. These are some Activity 3 feedback quotes shown immediately below which also agree with a similar exit survey question in the following paragraph about "one thing...you could readily implement in your class next semester"

"Most useful tool = muddiest point/concept warehouse; most likely technique = muddiest point; other tools = camstudio (free screencasting), wikimedia (pictures/diagrams), Commons, Udacity (model for on-line instruct), wordle (word clouds)"

"Cybertools: Quizlet, concept inventory hub has high potential to be used as an assessment tool” "Innovation willing to try-everything; I am always eager to try and learn. Which ones I will definitely use: muddiest points (love it) and Milo’s concept warehouse”

Exit Survey comments on the question, "As a teacher or faculty member, what is the one thing that you learned from this workshop that you could readily implement next semester in one of our classes?

- Concept warehouse \& muddiest points

- Muddiest points w/ world cloud, from table discussion - will look into SM Physics, Socrative.com, turnitin.com; "Students like to see their own quotes" - I didn't do that before

- I will work to implement a digital form of "muddiest point” for checking for understanding

- I will definitely use a concept inventory. Possibly Quizlet \& some short YouTube videos

- I’ll explore Quizlet for basic courses

- Muddiest point

- Muddiest point - Very likely

- Use of CI. There is none in software engineering and may require to be developed

- Muddiest points, Quizlet vocabulary. I will continue my search of concept inventory on first year Calculus. Thank you, it was a great workshop!!! :;

- I was not aware of these tools, how do I learn more about these tools? These tools should be built into Blackboard or other course management tools. 
- High likelihood of adding Cyber tools. My students are forever on their i-things anyhow might as well direct it toward learning

- I already use some of the stuff that was mentioned - Socrative, Flashcard, Videos for helping students at home

- Muddiest points surveys - app in smart phone would be great to tabulate "instantly" on muddiest points - with word cloud

- Muddiest point

- Muddiest point (especially the app if it is developed); Quizlet.com

- Muddiest point, highly likely

- Muddiest point

Of the 17 exit survey responses listed above, 10 of those included Muddiest Points, which demonstrates the potential buy in for their use across a range of disciplines of the concept of twoway feedback for improving instructor teaching and student learning.

\section{Goal Six on Effectiveness of JTF Project Tools and Strategies Dissemination}

For goal six on the effectiveness of dissemination of JTF project tools and strategies, the working objective was to characterize the extent to which JTF strategies, resources, products and findings have been disseminated, demonstrated and used by engineering instructors, programs, and book publishers.

Multiple strategies used to disseminate JTF pedagogy and resources included the following.

- First, as a result of discussions with Wiley Publishing, they will be adapting four types of JTF teaching and learning resources into the Wiley Plus e-learning student resource which is linked to two widely-used materials texts. The resources include: 35 Muddiest Point Tutorial and Example Problem videos; a Muddiest Point data collection tool; and an electronic vocabulary building e-flash card resource, and vocabulary term-and definition multiple choice questions.

- Second, two types of instructor Just-in-Time-Teaching tools were developed for the Concept Warehouse. One tool was the end-of-class, Muddiest Point Student Reflection sheet which was web-enabled for easy, automated data collection and reporting. The other tool was a collection of 114 ConcepTest question sets used for classroom clicker questions or pre-post topic concept quizzes.

- Third, three types of JTF student Just-in-Time learning resources were developed for use on open web sites. These included an e-flashcard vocabulary building site a Quizlet.com, JTF Muddiest Point YouTube videos, and also a repository of all the original slide sets from YouTube videos at SlideShare.com. Students can download the slide sets at SlideShart.com and then can take notes on them while they are watching the Muddiest Point YouTube videos.

- Fourth, the principles, practices and resources of JTF pedagogy were presented and published at 4 conference talks (40-60 people), at a well-attended conference workshop (28) and also distributed via CD to individuals at the workshop and the conference talks and poster. The positive outcomes of the ASEE2013 workshop were discussed earlier in the Goal Five section on "Potential of Using JTF in Other Engineering Domains." 


\section{Summary and Conclusions}

The principal disciplinary field of the project has been engineering education directed toward the subject of materials science and engineering, although the disciplines of students in the classes include mechanical, chemical, industrial, materials, and a few other engineering disciplines. That said, the types of strategies, tools, and resources created for the JTF project could be used in all other engineering domains. The types of general tools that were created could be used by all instructors if they wanted to use the technologies for their own disciplinary use. The Concept Warehouse Muddiest Point Data collection and reporting tool could be used universally. Content on other tools would have to be created for the discipline. These tools include Concept Warehouse ConcepTests as well as specific disciplinary material for Muddiest Point YouTube videos, vocabulary terms for Quizlet and YouTube slide sets for SlideShare.

Overall, 15 months into the JTF project the results have been positive and encouraging, although impediments have been encountered, but are being addressed. They are summarized as highlights from the six goals of the JTF project include the following. For goal one, new resources, two new web-enabled instructor tools have been created on Concept Warehouse including over 1600 Conceptests and automated Muddiest Point collection and reporting. For student resources, YouTube Muddiest Point videos have had over 140,000 views and have acquired over 1200 subscribers. For goal two, building a community of practice, instructors have identified a common set of barriers to implementing JTF pedagogy and are collaborating to address and overcome them. For goal three, instructor change, a survey showed that being involved in the JTF project has: 1) made them more reflective teachers; 2) had motivated them to change their classroom practice; 3) had made their students more engaged as a result of the changes they were implementing in my classroom teaching practice; 4) helped them better understand their students' learning. For goal four, impact on student attitude, learning and persistence, the students persisted in the JTF classes at a level of 97\% while they also found high interest and value in using Muddiest points at relatively low cost. For goal five, JTF potential for impacting other engineering domains, an ASEE 2013 workshop had 28 participants who unanimously agreed that envision incorporating at least one of the web-based teaching and learning strategies from the workshop into their course(s). Finally, for goal six, broad dissemination, impact has been shown with Wiley publishing utilizing four similar strategies to those used in JTF as detailed in the next paragraph.

There is the possibility that there will be specific impact on the area of undergraduate education in materials science and engineering since Wiley Publishing will be using four of the instructor and student tools on their Wiley Plus student e-learning resource site. Since the two Wiley materials textbooks are widely used among a field of 60,000 books published for introductory materials science texts, there is very good potential for impact on teaching and learning in the topical area of materials science, as well as subjects and courses in other engineering domains.

\section{Acknowledgement}

The authors from the four collaborating institutions acknowledge the support of this work from NSF Grant \#1226325. 


\section{Bibliography}

1. Bateman, G. R. \& Roberts, H. V. (1995). Two-way fast feedback for continuous improvement of teaching and learning. Quality Progress, 28(100), 168.

2. Butler, D. L. \& Winne, P. H. (1995). Feedback and self-regulated learning-A theoretical synthesis. Review of Educational Research, 65(3), 245-281.

3. Krause, S., Baker, D.R., Carberry, A.R., Koretsky, M., Brooks, B.J., Ms. Gilbuena, D., Waters, C., and Ankeny, C.J. (2013) Just-in-Time-Teaching with Interactive Frequent Formative Feedback (JiTTIFFF or JTF) for Cyber Learning in Core Materials Courses", 2013 ASEE Proceedings.

4. Carberry, A.R., Krause S.J., Ankeny C.J., and Waters, C. (2013) Unmuddying” Course Content Using Muddiest Point Reflections 2013 FIE Proceeding).

5. Nicol, D. J. \& Macfarlane-Dick, D. (2006). Formative assessment and self-regulated learning: A model and seven principles of good feedback practice. Studies in Higher Education, 31(2), 199-218. 